\title{
PENYUSUNAN MATERI PEMBELAJARAN UNTUK MENINGKATKAN KETERAMPILAN BERBICARA UNTUK SANTRI PONDOK YANABI'UL ULUM WALHIKAM
}

\author{
Faruq Abdul Muid \\ Sekolah Tinggi Ilmu Bahasa Arab dan Dakwah Masjid Agung \\ Sunan Ampel Surabaya \\ faruqabdulmuid@stibadamasa.ac.id
}

\begin{abstract}
Abstrak
Dalam penelitian ini, peneliti menggunakan penelitian eksperimen. Peneliti telah melakukan observasi terlebih dahulu sebelum melakukan penyusunan materi pembelajaran di Pondok Pesantren Yanabi'ul 'Ulum Wal Hikam Sidoresmo Surabaya. Setelah mendapat data yang diperlukan, mulailah peneliti mengembangkan materi ajar yang sesuai dengan kebutuhan santri Pondok Pesantren Yanabi'ul 'Ulum Wal Hikam. Dan mengukur efektifitas pengembangan materi ajar yang telah tersusun sehingga menjadi materi ajar yang efektif dan bermanfaat untuk santri Pondok Pesantren Yanabi'ul 'Ulum Wal Hikam Sidoresmo Surabaya. Peneliti menggunakan kelas eksperimen dan kelas kontrol. Dalam pelaksanaannya rata-rata yang didapatkan santri di kelas eksperimen 8 dan yang didapatkan santri di kelas kontrol 7. Dan peneliti menganalisis hasil dari test tersebut dengan menggunakan rumus One Sample T-Test. Dengan Hipotesis Ho: tidak ada perbedaan antara hasil dari kelas eksperimen dan kelas kontrol, Ha: ada perbedaan anatara kelas eksperimen dan kelas kontrol. Dan hasil penghitungan rumus T-Test menunjukkan bahwa T-Hitung lebih besar dari T-Tabel $(2,032<14,512>2,728)$, maka terdapat perbedaan antara kelas eksperimen dan kelas kontrol. Maka terdapat efektifitas dari penggunaan materi ajar yang disusun dalam pengembangan kompetensi berbicara santri dalam pembelajaran bahasa Arab di Pondok Pesantren Yanabi'ul ‘Ulum Wal Hikam Sidoresmo Surabaya.
\end{abstract}

Kata kunci: Materi Pembelajaran, kompetensi berbicara, penyusunan, efektifitas 
Faruq Abdul Muid : Penyusunan Materi Pembelajaran untuk Meningkatkan Keterampilan Berbicara untuk Santri Pondok Yanabi'ul Ulum Walhikam

\section{ملخص - 20 - n}

في هذه الدراسة، استخدم الباحثون البحث التجريبي. أبدى الباحثون ملاحظاتهم قبل إعداد المواد التعليمية في مدرسة ينابيع العلوم والحكم سيدورسمو الإسلامية الداخلية في سورابايا. وبعد الحصول على البيانات اللازمة، بدأت الباحثة في تطوير المواد التعليمية حسب احتياجات طلاب مدرسة ينابيع العلوم والحكم الداخلية الإسلامية. وقياس فاعلية تطوير المواد التعليمية التي تم تنظيمها بحيث تصبح مواد تعليمية فعالة ومفيدة لطلاب مدرسة ينابيع العلوم والحكم سيدورسمو الداخلية الإسلامية في سورابايا. استخدم الباحثون الفئة التجريبية والطبقة الضابطة. عمليا ، المعدل الذي حصل عليه الطلاب في الصف التجريبي ^ وتلك التي حصل عليها الطلاب في الصف السابع • وقام الباحثون بتحليل نتائج الاختبار باستخدام صيغة One Sample. T-Test يوجد فرق بين الصنف التجريبي والفئة الضابطة. وتظهر نتائج حساب

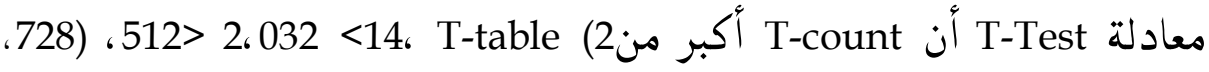
لذلك هناك فرق بين الصنف التجريبي وفئة التحكم. لذلك هناك فاعلية لاستخدام المواد التعليمية المرتبة في تطوير كفاءة التحدث لدى الطلاب في تعلم اللغة العربية في مدرسة ينابيع العلوم والحكم سيدوريسمو الإسلامية الداخلية في سورابايا. الكلمات المفتاحية : المواد التعليمية، كفاءة التحدث ، التجميع ، الفعالية 
Faruq Abdul Muid : Penyusunan Materi Pembelajaran untuk Meningkatkan Keterampilan Berbicara untuk Santri Pondok Yanabi'ul Ulum Walhikam

\section{مقدمة}

اللغة العربية لغة نزل بها القران ونطق بها النبي والصحابة الكرام،

وليس يُعدّ غريبا أن هذه اللغة من الدين بالضروري لأنها وسيلة لفهم معاني القران الكريم والأحاديث الشريف ومعرفة مقاصد الشريعة والأحكام الدينية. تعتبر اللغة العربية بتراثها الأدبي الضخم من إحدى اللغات العظيمة في العالم. فمند العصور الوسطى تـمتعت هذه اللغة بالعالمية التي جعلتها إحدى لغات العالم العظيمة، مثل اللغة اليونانية و اللاتينية و الإنجلزية والآسبانية والروسية. وهذا الوضع بالنسبة للعربية، لا يعكس عدد المتكلمين بها فقط. بل يعكس أيضا المكانة التي احتلتها في التاريخ وما تزال تلعبه في تنمية المجتمات العربية والإسلامية.

وقد ذكر العالم اللغوي العظيم فرجوسون أن اللغة العربية بالنسبة إلى عدد المتكلمين بـها و بالنسبة إلى مدى تأثيرها تعتبر أنها أعظم اللغات السامية اليوم و ينبغي أن تعتبر من إحدى أهم اللغات في العالم . وهي اليوم من إحدى اللغات التي تكتب بها وثائق الأمم المتحدة، وأيضا ، أنّ اللغة العربية الآن من اللغات المدروسة في الأماكن الكثيرة في العالم ، وخاصة في الولايات المتحدة. عج تعلّم اللغة العربية وتعليمها في المعاهد الإسلامية في جاوة الشرقية ليس بغريب. لأن المعاهد هي مراكز التعليم للعلوم الدينية، والكتب الدينية أكثرها

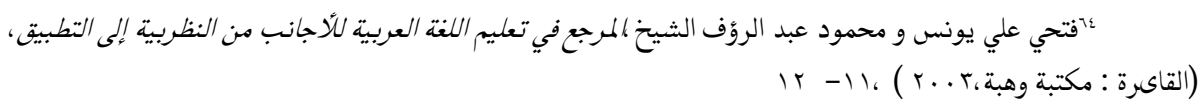


Faruq Abdul Muid : Penyusunan Materi Pembelajaran untuk Meningkatkan Keterampilan Berbicara untuk Santri Pondok Yanabi'ul Ulum Walhikam

جاءت باللغة العربية. إذا ، فمن الضرورة تزويد الطلبة لإجادة هذه اللغة. لأنها كمفتاح لفتح أبواب العلوم الدينية. تعليم هذه اللغة بالمعهد الإسلامي ينابيع العلوم الحكم ينبني علي أساس القواعد و الترجمة لأنها كوسيلة لفهم الكتب الفقهية وكتب التفاسير أو غيرها من كتب التراث مع أن اللغة هي وسيلة للاتصال . ومن هذا الجانب أن أكثر الطلبة في هذا المعهد وفي أكثر المعاهد السلفية لا يستطيعون أن يستخدم اللغة العربية في الكلام مع أنهم يقرؤن ويفهمون الكتب العربية بل بعضهم قد يكتبون الكتب باللغة العربية.

ثم أن الكتاب المستخدم لتعليم اللغة اللعربية ينظر فيه أنه صعبة للطلبة المبتدئين مع خلفية دراساتهم. ورأى الباحث أن الطلبة لا يهتم بالدرس لأن الموضوعات فيها أكثرها لا تناسب بثقافيتهم مع أن مواد التعليم الفعال هو الذي تناسب بثقافية الطلاب ومن الجانب اللغوي أن المادة في هذا الكتاب غير معاصرة ويحتاج إلى تجديد . وهذا الكتاب لا يقدم كثيرا من الأمثلة التي تساعد الطلبة وتشجّعهم في الكلام . والهدف الأولى لتعليم اللغة العربية هو لتزويد الطلبة لتنمية كفاءاتهم في المهارات اللغوية الأربع لا سيما مهارة الكلام. بناء على ذلك أراد الباحث أن يعد المواد التعليمية المطورة لطلبة الفصل الثاني الابتدائي بمعهد “ينابيع العلوم و الحكم” السلفي الإسلامي سيدورسمو 
Faruq Abdul Muid : Penyusunan Materi Pembelajaran untuk Meningkatkan Keterampilan Berbicara untuk Santri Pondok Yanabi'ul Ulum Walhikam

سورابايا التي تناسبهم من حيث موضوعاته في ثقافيتهم المعاصرة مع أمثلة الحوار و التدريبات التي تعينهم و تشجعهم في الكلام . منهج البحث

المنهج المستخدم في هذا البحث هو المنهج التجريبي على المدخل الكيفي الكمي. لأن مقياس ما حصل في البحث يحتاج إلى الأرقام والجداول والإحصاء ، فلذلك يستخدم المنهج الكمي • ولكن بيان هذا البحث لم يتكامل إلاّ

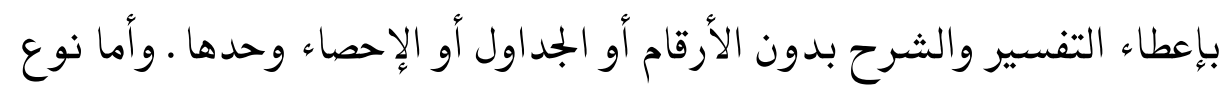
البحث المستخدم في هذا البحث فهو البحث التطويري لأنه مستخدم لإنتاج النتائج وهي المواد التعليمية وتجربة فعاليته. المواد التعليمية

المواد جمع مادة وهي لغة ما يتركب منه الثي؛ ويقوم بهُ10. المواد التعليمية هي مجموعة الخبرات التربوية والحقائق والمعلومات التى يرجى تزويد الطلاب بها ، والإتجاهات والقيم التى يراد تنميتها عندهم، أو المهارات الحركية التى يراد اكتسابها إياهم ، يهدف تحقيق النمو الشامل المتكامل لهم فى ضوء الأهد اف المقررة في المنهج "ج . وهي أيضا بمعنى كل شي؛ يمكن استخدامه لمساعدة المدرس في أنشطة التعليم. والمواد التعليمية تتكون من المعرفة (الحقائق والمفاهيم والمبادئ والإجراءات) والمهارات، والمواقف أو كوسيلة لتحقيق المعايير

$$
\begin{aligned}
& \text { WWW.almaany.com ، معجم الرائد }
\end{aligned}
$$

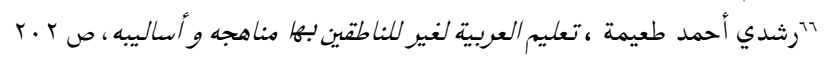


Faruq Abdul Muid : Penyusunan Materi Pembelajaran untuk Meningkatkan Keterampilan Berbicara untuk Santri Pondok Yanabi'ul Ulum Walhikam

والكفاءات الأساسية المنشودة. 'ّ وعرّف ويينا سنجايا Wina Sanjaya) المادة التعليمية تعني كل محتويات يتم إعدادها في المنهج الدراسي المتبع تحقيقا على معايير الكفاءة في وحدة التعليم المعين.`^ومن ذلك يُعرف أن المواد التعليمية هي مجموعة الخبرات التربوية والحقائق والمعلومات التي تحتوي على المعايير والكفاءات الأساسية المنشودة لمساعدة المدرس في أنشطة التعليم. وتشتمل المواد التعليمية على بعض العناصر الأساسية التي يلزم بوجودها ، وهي: دليل المعلم والأهداف الدراسية المنثودة و المعلومات و التدريبات و دليل العمل، مثل كتاب التدريبات الإضافي و التقويم • رأي عبد

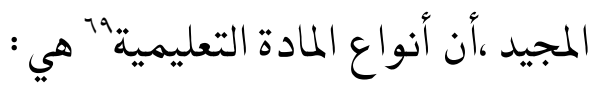
1- المادة التعليمية المطبوعة، مثل كتاب، نشرة، صورة وغير ذلك. r- المادة التعليمية السمعية، مثل الشريط والمذياع وغير ذلك. r- المادة التعليمية السمعية الصرية، مثل التلفيزيون والفيديو أو أفلام ع- المادة التعليمية التفاعلية، مثل الوسائط المتعددة التفاعلية (Multimedia Interaktif) الأهداف والعوامل المؤثرة والأسس في إعداد المادة التعليمية

Arman Husni, " Pengembangan bahan ajar bahasa arab", al : يترجم من ittijah, Vol. 02 No. 01 ( Januari-Juni), 49 Wina sanjaya, Perencanaan dan desain sistem pembelajaran ( يترجم من ( Jakarta: Kencana, 2010 ) Cet 3, 142 Arman Husni, " Pengembangan bahan ajar bahasa arab", 49 " 19 
Faruq Abdul Muid : Penyusunan Materi Pembelajaran untuk Meningkatkan Keterampilan Berbicara untuk Santri Pondok Yanabi'ul Ulum Walhikam

الأهداف في القيام بإعداد مواد تعليمية هي انتاج المواد التعليمية المناسبة بالأهداف الدراسية العامة والخاصة والأهداف الدراسية الإضافية. وتصميم المواد التعليمية المناسبة بتركيب محتويات الدرس وخصائصها كل واحدة منها ـ ولترتيب الموضوعات المقدمة في الدراسة ترتيبا منطقيا ـ وتفتح إمكانية تطوير المواد التعليمية استمراريا المتبعة بتطور التكنولوجي لم أما العوامل المؤثرة في إعداد المادة التعليمية فهي صدق مضمون النص ودقة المحتوىات وسهولة الاستخدام ومفهومها واخيار الأنماط اللغوية المناسبة بمستوى الدارس وتزيين المادة المصممة وتوضيح المادة بالصور أو الرمز أو رسم بياني وغير ذلك وكمال العناصر من عنصر تعليمي الأساسي والثانوي والتقويم وأما الأسس التي تعين على إعداد المواد التعليمية وعلى تقويها فهي : 1 - الأسس الثقافية والاجتماعية

عند إعداد كتاب لتعليم اللغة العربية للأجانب فتنبغي أن تكون له طابعة اجتماعي وثقافي إسلامي • و أن يتضمن المحتوى التعليمى للكتاب عناصر الثقافة المادية والمعنوية بصورة تتناسب وأغراض الدارسين

$$
\text { r الأجانب. الأسس السيكولوجية }
$$

Arman Husni, " Pengembangan Bahan Ajar Bahasa Arab ", 49 " يترجم من v. 
Faruq Abdul Muid : Penyusunan Materi Pembelajaran untuk Meningkatkan Keterampilan Berbicara untuk Santri Pondok Yanabi'ul Ulum Walhikam

إن المتعلم يشكل عنصرا أساسيا في العملية التعليمية، فهو المحور

الذي تركز عليه، وأنه هو أولا وأخيرا بالهدف من العملية التعليمية، فما

قامت هذه العملية إلا من أجل تحقيق أهداف معينة لدى المتعلمة ، ومن ثم

فإن معرفة خصائص التعلم النفسية والعقلية تعد مطلبا ضروريا عند إعداد

$$
\text { محتوى المناهج الدراسية. }
$$

وبيّن محمد كامل الناقة و رشدي أحمد طعيمة الأسس النفسية ينبني أن تراعي عند وضع مادة تعليمية أساسية لتعليم اللغة العربية لغير الناطقين بها وهي ما يلي

أ- - أن تناسب المادة الخصائص النفسية والثقافية للد ارسين مفرقة في ذلك بين ما يقدم للصغار و ما يقدم للكبار وتراعي المادة الفروق بين ميول

$$
\text { واهتمامات وأغراض الدارسين من تعلم اللغة }
$$

ب- أن تحدد مكانة كلّ مهارة من مهارات اللغة في المادة المقدمة وما ينبني أن يعطي لكلّ منها من هذه المادة . وكذا الأداء المطلوبة في كلّ مهارة من

$$
\text { مهارات اللغة ومراعاة ذلك في المراحل المختلفة من المادة. }
$$

ج- أن يتتابع تقديم المهارات وفق خطة واضحة تتناسب وتدرج مراحل نضج الدارسين بحيث لا تقدم المهارة إلّا في وقتها المناسب.

$$
\text { د - أن تلتفت المادة إلى المهارات بشكل تفصيلي }
$$

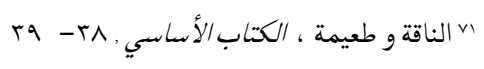

\section{IHTIMAM}


Faruq Abdul Muid : Penyusunan Materi Pembelajaran untuk Meningkatkan Keterampilan Berbicara untuk Santri Pondok Yanabi'ul Ulum Walhikam

هـ - أن تحقق المادة المطالب الأساسية للدارسين من تعلم اللغة. وأن تكون مشوقة جامعة بين الفكاهة والحكاية والنادرة وكلّ ما من شأنه أن يحقق

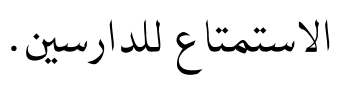

و- أن تراعي المادة الفروق الفردية بين الدارسين في القدرات عن طريق

التنوع في المستوى والمادة استعداد الدارسين للتعلم، وأن تلجاً إلى

$$
\text { وسائل متعددة لتنشيط هذا الاستعد اد وتهيئة الدارس للتعلم. }
$$

ز- أن تحقق المادة للدارس نوعا من الإشباع أي تمكنه وبشكل سريع من إتمام

$$
\text { عملية اتصال باللغة سماعا وحديثا . }
$$

ح- أن تراعي المادة إثارة رغبة الدارسين واستعداداتهم لتعرف اللغة وزيادة معلوماتهم وإثباع حب استعلاطهم نحو ثقافتهم وذلك عن طريق

$$
\text { الأنشطة والممارسات. }
$$

ط- أن يستند إعداد المادة وتنظيمها إلى ما انتهت إليه نظريات التعلم من حقائق ومفاهيم • وتصاغ المادة وتنظم في ضوء الطرق الفعالة في تدريس

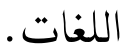

ي- أن تهيي المادة دائما للدارس مشكلة يحاول التغلب عليها عن طريق تعلم اللغة وممارستها وتتيح المادة للدارس فرصا تشجعه على استخدام ما تعلم

$$
\begin{aligned}
& \text { في مواقف اتصال حقيقية شفوية وتحريرية. } \\
& \text { r- الأسس اللغوية والتربوية }
\end{aligned}
$$


Faruq Abdul Muid : Penyusunan Materi Pembelajaran untuk Meningkatkan Keterampilan Berbicara untuk Santri Pondok Yanabi'ul Ulum Walhikam

ثم إنّ لإعداد المادة التعليمية لتعليم الكلام لطلاب بالفصل الثاني بـمعهد ينابيع العلوم والحكم سيدورسمو سورابايا سبع خطوات. أولا جمع المعلومات في تعليم الكلام ـ ثانيا التخطيط ـ ثالثا إعداد المادة التعليمية لتعليم الكلام. رابعا مراجعة الخبراء ـ خامسا تجربة المادة لتعليم الكلام. سادسا تحسين المادة التعليمية لتعليم الكلام وسابعا تجربة إجراء المادة التعليمية لتعليم

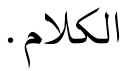

\section{مهارة الكلام}

والكلام باعتبار الأسلوب الطبيعى للتعامل بين الناس وبوظيفته لتبادل

الأفكار بينهم لها أهمية كثيرة فينبغي للناس أن يتمكن من إجادته، ومن أهمية مهارة الكلام هي أن الكلام كوسيلة الإفهام سبق الكتابة في الوجود ، فالإنسان تكلم قبل أن يكتب . و الحياة المعاصرة بما فيها من حرية وثقافة في حاجة ماسة إلى المناقثة، وإبداء الرأي، ولا سبيل إلى ذلك إلا بالتدريب الواسع على التحدث الذي يؤدي إلى التعبير الواضح عما في النفس. والكام نثاط إنساني يقوم به الصغير والكبير، والمتعلم والجاهل، والذكر والأنثى، حيث يتيح للفرد فرصة أكثر في التعامل مع الحياة، والتعبير عن مطالبه الضرورية. و الكلام وسيلة رئيسة في العملية التعليمية في مختلف مراحلها ، لا يككن أن يستغني عنه معلم في أية مادة من المواد للشرح والتوضيح.

\section{IHTIMAM}


Faruq Abdul Muid : Penyusunan Materi Pembelajaran untuk Meningkatkan Keterampilan Berbicara untuk Santri Pondok Yanabi'ul Ulum Walhikam

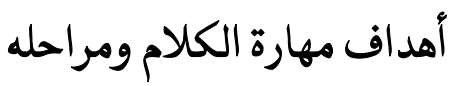

هناك أهداف لتعليم الكلام للناطقين بغير العربية، منها مايلي :

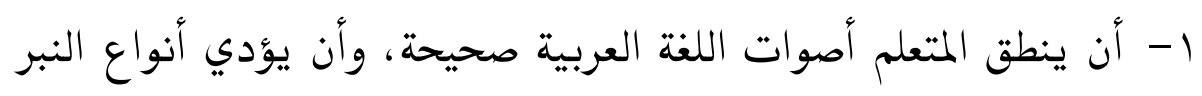

$$
\begin{aligned}
& \text { والتنغيم المختلفة وذلك بطريقة مقبولة من أبناء العربية } \\
& \text { r- أن ينطق الأصوات المتجاورة والمتنشابهة }
\end{aligned}
$$

r- أن يدرك الفرق في النطق بين الحركات القصيرة والحركات الطويلة

ع - أن يعبر عن أفكاره باستخدام الصيغ النحوية المناسبة.

ه- أن يعبر عن أفكاره باستخدام النظم الصحيحة لتركيب الجملة في العربية

$$
\begin{aligned}
& \text { خاصة في الكلام، وغير ذلك. } \\
& \text { هناك مر احل لتدريس الكلام : } \\
& \text { 1- المرحلة الأولى : حوارات مغلقة الإجابة }
\end{aligned}
$$

مرحلة مبتدئية من مراحل التدريب على مهارة الكلام يغلب

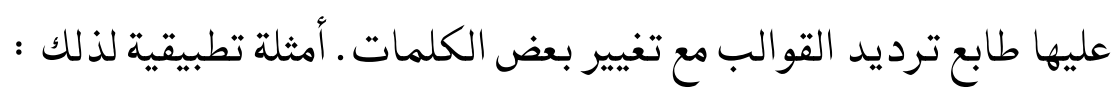

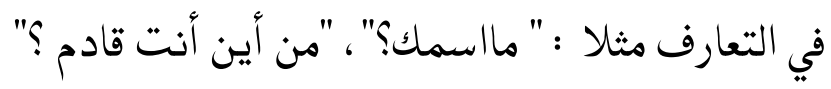

$$
\begin{aligned}
& \text { r- المرحلة الثانية : حوارات مفتوحة الإجابة }
\end{aligned}
$$

وهي مرحلة تختلف عن المرحلة الأولى بزيادة المتطلبات الفكرية

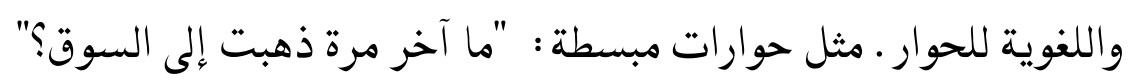

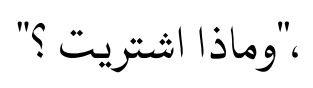


Faruq Abdul Muid : Penyusunan Materi Pembelajaran untuk Meningkatkan Keterampilan Berbicara untuk Santri Pondok Yanabi'ul Ulum Walhikam

r- المرحلة الثالثة : التعبير الموجه أو المقيد ; التعبير عن الأفكار القصيرة. في هذه المرحلة يتولى الطالب التعبير عن فكرة متكاملة, ولكن بتقديم بعض المساعدة على مستوى الأفكار أو اللغة أو كليهما . مثل : عرض صورة لوصفها, عرض سلسلة من الصور لتكوين القصة, أو وصف تفصيلي لمحتويات صور متفرقة, أو التخليص . ع - المرحلة الرابعة : التعبير الحر ; التعبير عن أفكار عميقة تعتبر هذه المرحلة التي تناسب بالمستويات المتقدمة من تعلم اللغة,و يقوم فيها الطالب بتقديم موضوعات متكاملة شخصيا ويعتمد على قدراته في التنظيم اللغوي والفكري.

\section{عروض البيانات عن تطوير المادة التعليمية لمهارة الكلام}

يبداً الباحث إجراء البحث التطويري بجمع المعلومات في تعليم الكلام

بمعهد ينابيع العلوم و الحكم ، ويقوم الباحث بجمع المعلومات فيها قبل أن يبداً الباحث بتصميم المادة التعليمية، وهو جمع المعلومات عن المثكلات التي يواجهها الطلاب في عملية التعليم وما يحتاجون إليه في الأنثطة التعليمية اللغوية . وأما المثكلات الموجهة التي وجدها الباحث في الملاحظة والمقابلة مع بعض الأساتيذ بعهد ينابيع العلوم والحكم فهي المثكلة التي تتعلق بمنهج تعليم الكلام ، والمشكلة التي تتعلق بطرائق تعليم الكلام، والمشكلة التي تتعلق بمادة تعليم الكلام ، والمثكلة التي تتعلق باختبار الكلام .

\section{IHTIMAM}


Faruq Abdul Muid : Penyusunan Materi Pembelajaran untuk Meningkatkan Keterampilan Berbicara untuk Santri Pondok Yanabi'ul Ulum Walhikam

بعد معرفة المثكلات المتعلقة بتعليم الكام في الفصل بعهد ينابيع العلومو الحكم ، يقوم الباحث بتصميم المادة التعليمية . وهناك تسعة دروس على

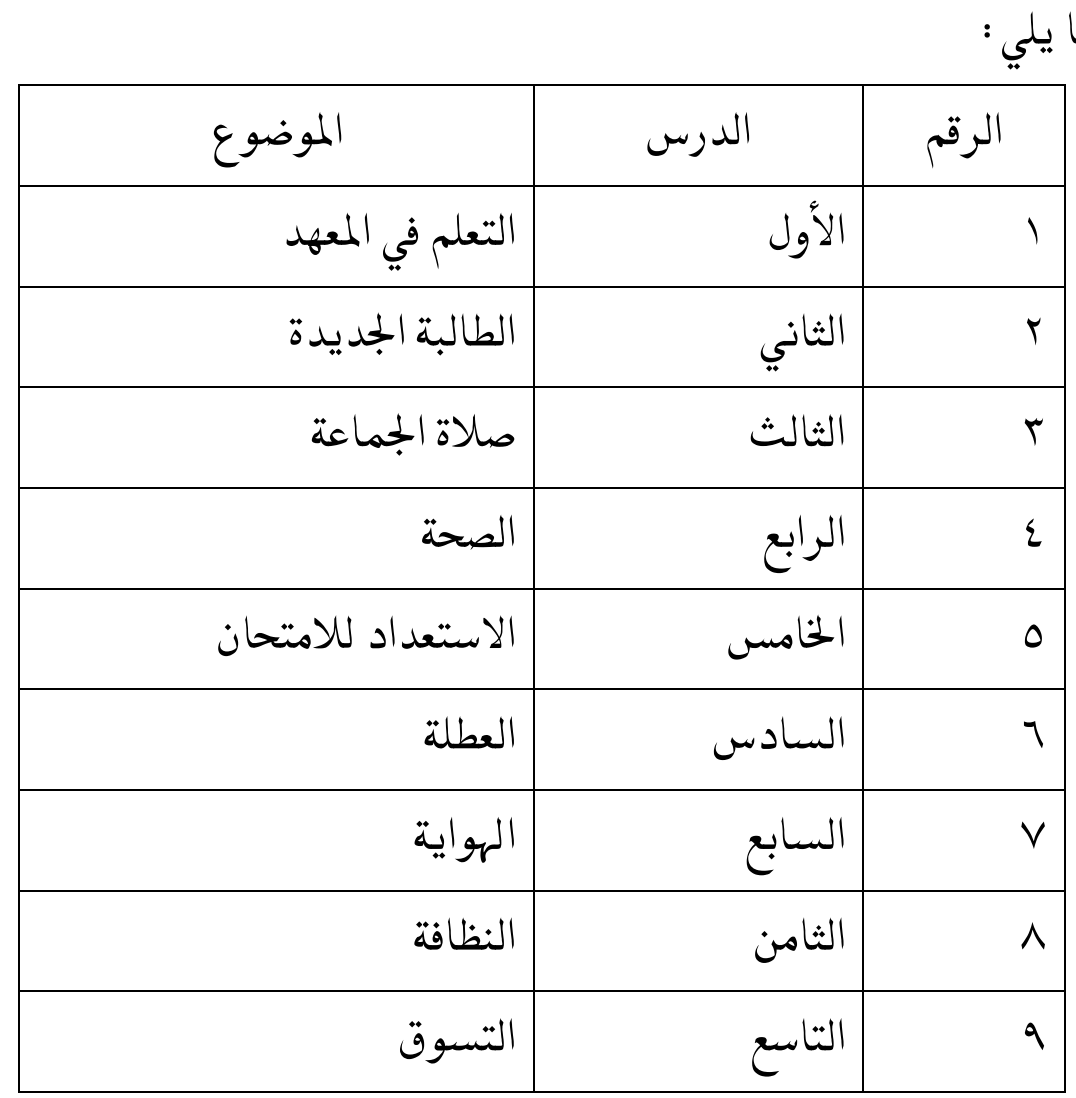

$$
\begin{aligned}
& \text { ولكل درس يجتوى على الثكل ما يلى : } \\
& \text { أ) ألمفردات الجديدة } \\
& \text { ب) إن الحوار } \\
& \text { ج) الأسئلة الاستيعابية } \\
& \text { د ) التدريب الأول }
\end{aligned}
$$


Faruq Abdul Muid : Penyusunan Materi Pembelajaran untuk Meningkatkan Keterampilan Berbicara untuk Santri Pondok Yanabi'ul Ulum Walhikam

$$
\begin{aligned}
& \text { ه) التدريب الثاني } \\
& \text { و) القاعدة النحوية } \\
& \text { ز) التدريب على القاعدة } \\
& \text { ح) لعبة لغوية. }
\end{aligned}
$$

وبعد أن ينتهي الباحث عن بإعداد المادة التعليمية لتعليم الكلام ،

يستمر الباحث الخطوة الآتية وهي مراجعة الخبراء تعني تصحيح المادة التعليمية

التي صمّمها الباحث، وهذه الحطوة تعتبر من الخطوة المهمة بعد تطوير المادة

التعليمية ليعرف الباحث الأخطاً والنقصان الموجودة في المادة التعليمية المطورة.

\begin{tabular}{|c|c|}
\hline \multicolumn{2}{|c|}{ معيار تقدير درجة لمهارة الكلام } \\
\hline النتيجة & 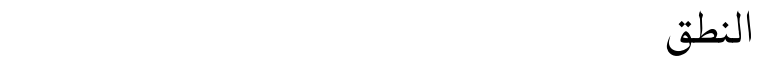 \\
\hline 0 & يخالطه أثر قليل جدا من اللكنة الأجنبية \\
\hline$\varepsilon$ & مفهوم بوضوح ، ولكن هناك لكنة اُجنبية واضحة \\
\hline
\end{tabular}

أما مقياس الدرجات المستخدمة لمراجعة الحبراء فهو ما يلي :

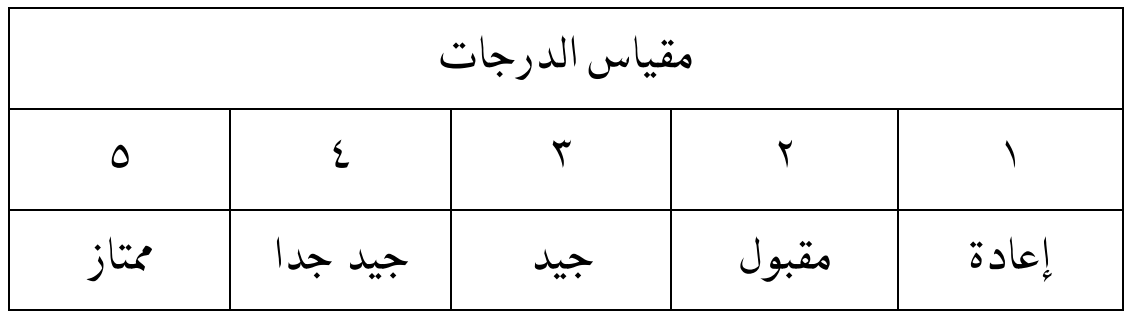

وحاصله ما يلي : 
Faruq Abdul Muid : Penyusunan Materi Pembelajaran untuk Meningkatkan Keterampilan Berbicara untuk Santri Pondok Yanabi'ul Ulum Walhikam

\begin{tabular}{|c|c|}
\hline$r$ & سشكلات نطقية تستدعي استماعا مركزا ، وأحيانا تؤدي إلى \\
\hline$r$ & بصعب فهمه بسبب مشكلات نطقية، ويطلب منه ما يقوله \\
\hline 1 & لديه مثكلات نطقية عويصه تجعل حديثه غير مفهوم تمام \\
\hline & 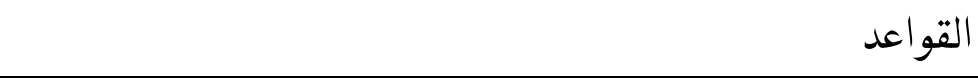 \\
\hline 0 & أخطاً القواعد وترتيب الكلمات قليلة لا تذكر \\
\hline$\varepsilon$ & يقع أحيانا في أخطاء نحوية لكنها لا تسبب غموضا \\
\hline$r$ & من حين لآخر يقع في أخطاء نحوية تسبب غموضا في المعنى \\
\hline$r$ & وأخطاء القواعد تجعل الفهم مستعسيا مما يجعله يعيد صياغة جمله \\
\hline 1 & أخطاؤه النحوية كثيرة إلى درجة تجعل حديثه غير مفهوم تماما \\
\hline & المفردات \\
\hline 0 & يستعمل المفردات والعبارات الاصطلاحية كمتحثدثى اللغة تماما \\
\hline$\varepsilon$ & 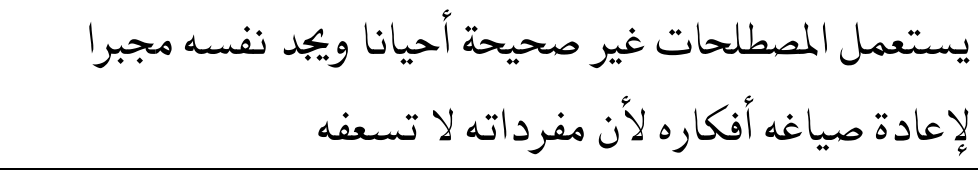 \\
\hline$r$ & حصيلته من المفردات كلمات خاطئة باستمرار ـ كلامه محدود وقليل لاًّن \\
\hline$r$ & الصتعمله الخاطيء للكلمات وقلة حصيلته من المفردات تجعل من \\
\hline 1 & محدودية ما عنده من مفردات تجعله غير قادر على الحديث تماما \\
\hline
\end{tabular}


Faruq Abdul Muid : Penyusunan Materi Pembelajaran untuk Meningkatkan Keterampilan Berbicara untuk Santri Pondok Yanabi'ul Ulum Walhikam

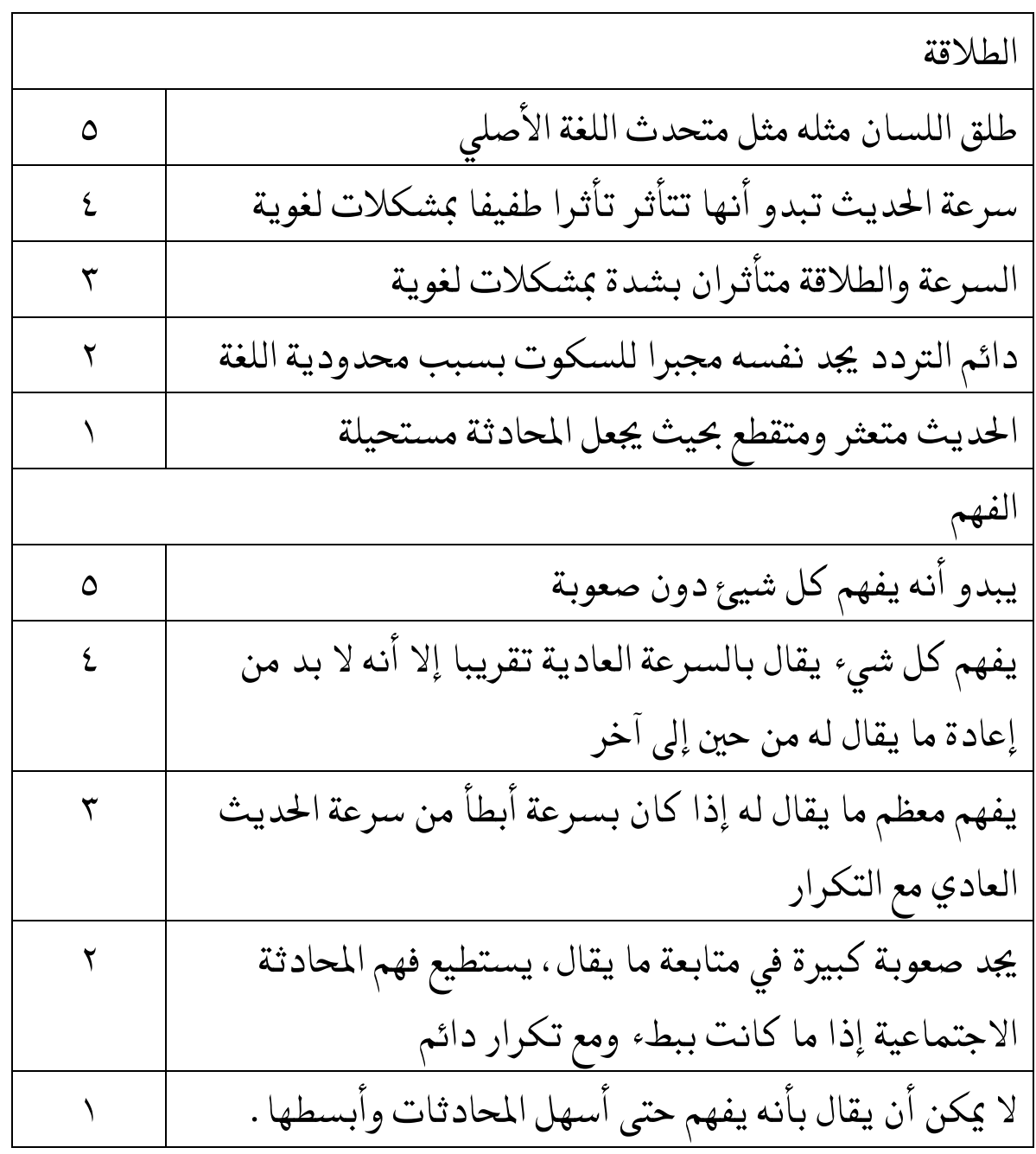

\section{تحليل البيانات}

ثم استمر الباحث الخطوة التالية بعد أن ينتهي من تحكيم الخبراء للمادة

التعليمية. وهذه الخطوة لنيل المعرفة عن فعالية المادة التعليمية في ميدان التعليم. وأراد الباحث أن يجرب هذه المادة التعليمية المطورة. وفعالية المادة التعليمية لا تعرف إلا بتجربة المادة التعليمية في ميدان تعليم، لأنها تحتاج 
Faruq Abdul Muid : Penyusunan Materi Pembelajaran untuk Meningkatkan Keterampilan Berbicara untuk Santri Pondok Yanabi'ul Ulum Walhikam

النتائج للقياس حتى يعرف الباحث فعاليتها ـ وبه يعرف الباحث الجوانب نقصان المادة التعليمية. واستعمل الباحث الفصل الضبطي والفصل التجريبي في هذا البحث.

وفي البداية عرض الباحث النتائج من الفصل الضبطي والفصل التجريبي

قبل استخدام المواد المطورة ليعرف كفائة الطلاب قبل التجربة، وكل فصل 11 طالبا ـ وها هو جدول النتائج للفصل الضبطي والفصل التجريبي بعد التجربة :

\begin{tabular}{|c|c|c|c|c|c|}
\hline المتتوسطة & الفصل التجريبي & رقم & النتبيجة & الفصل الضبطي & رقم \\
\hline$V V, r$ & محمد علما حارس & 1 & $V V, T$ & محمـد رزال براتاما & 1 \\
\hline$v 9,7$ & محمد لطفي & r & $T V, r$ & محمد فريد & r \\
\hline$\vee\urcorner, \varepsilon$ & دوي براسيتيو & r & u & محمد بدر الصالح & r \\
\hline$\wedge \uparrow, \wedge$ & ديماس مولانا & $\varepsilon$ & $09, r$ & محمد راضي & $\varepsilon$ \\
\hline$V, r$ & محمد سهري & 0 & $\vee \varepsilon, \varepsilon$ & سهراني & 0 \\
\hline$v a, r$ & محمد رفقي ذو الفقار & 1 & \urcorner$\wedge, \wedge$ & شمس العارفين & 1 \\
\hline$\wedge$. & مصطفى & V & 79,7 & سيف العالم & $\vee$ \\
\hline$\wedge 9,7$ & ماس سيتي رشيدة & $\wedge$ & $V \cdot, \varepsilon$ & إليا هرماواتي & $\wedge$ \\
\hline$\vee \varepsilon, \varepsilon$ & نادرا عين فوتري & 9 & $\vee\urcorner, \wedge$ & أمي يولياني سلمة & 9 \\
\hline$\vee\urcorner, \wedge$ & سكينة & 1 & $79, r$ & خيرات النساء & 1 \\
\hline
\end{tabular}


Faruq Abdul Muid : Penyusunan Materi Pembelajaran untuk Meningkatkan Keterampilan Berbicara untuk Santri Pondok Yanabi'ul Ulum Walhikam

\begin{tabular}{|c|c|c|c|c|c|}
\hline المتتوسطة & الفصل التجريبي & 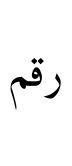 & المتوسطة & الفصل الضبطي & رقم \\
\hline VI & أنيسة فطرية & 11 & $V r, \varepsilon$ & راهاني & 11 \\
\hline ar & ليا مستفيدة & ir & $77, \varepsilon$ & ساهلة & Ir \\
\hline$\wedge\urcorner, \wedge$ & رزقا صفينا & ir & $V q, r$ & محيتي & ir \\
\hline$\Lambda V, r$ & عائشة & $1 \varepsilon$ & 70,7 & ديفاني & $1 \varepsilon$ \\
\hline$V \backslash, \varepsilon$ & يوليانا & 10 & $\vee \cdot, \wedge$ & زائدة & 10 \\
\hline$\wedge r, r$ & نور ليلة العرفة & 17 & 71,7 & أسوة الحسنة & 17 \\
\hline VT & جويرية & IV & $\vee\urcorner, \wedge$ & شفريدا & IV \\
\hline$\vee\urcorner, \wedge$ & نور عفيفة & $1 \wedge$ & $V \cdot, \varepsilon$ & سيتي نور هالزا & 11 \\
\hline $1 \varepsilon \varepsilon \wedge$ & المجموع & & IYTE & الـمجموع & \\
\hline
\end{tabular}

من جدول النتائج السابق يعرف أن أعلي النتائج المتوسطة من الفصل

التجريبي من خمس تجربات هي بو وعدد الطلبة الذين يحصل على هذه

النتيجة طالب واحد وأدنى النتائج المتوسطة هي YY و يحصل على هذه النتيجة

طالب أيضا ـ وأعلي النتائج المتوسطة من الفصل الضبطي من خمس تجربات هو

و و عدد Y V9

المتوسطة هو 9 ه ب و يحصل على هذه النتيجة طالب أيضا . 
Faruq Abdul Muid : Penyusunan Materi Pembelajaran untuk Meningkatkan Keterampilan Berbicara untuk Santri Pondok Yanabi'ul Ulum Walhikam

$$
\begin{aligned}
M x & =\frac{\Sigma x}{N x} \\
M x & =\frac{1448}{18} \\
& =80,42 \\
M y & =\frac{\Sigma y}{N y} \\
M y & =\frac{1264}{18} \\
& =70,24
\end{aligned}
$$

فالقيمة التي حصل عليها الفصل التجريبي (متغير X) هي rع . • ـ. أما القيمة التي حصل عليها الفصل الضبطي (متغير Y) فهي • ، ، Y . فبناء على اللوحات السابقة ونتيجة المتوسط من الفصل التجريبي والفصل الضبطي نعرف أن القيمة للفصل التجريبي الذي استخدم المواد المطورة أحسن من قيمة الفصل الضبطي. هذا الحال يدل على أن المواد المطورة أحسن من المواد القديمة. ولمعرفة النتيجة الأخيرة استخدم الباحث قاعدة Test T كما يلى :

X من متغير SD (standard Deviasi م أن يطلب الباحث

$$
\begin{aligned}
& \mathrm{SD}_{\mathrm{x}}=\sqrt{\frac{\Sigma x 2}{N}}=\sqrt{\frac{80,42}{18}} \\
& =\sqrt{4,468} \\
& =2,114
\end{aligned}
$$

2- من متغير SD (standard Deviasi أن يطلب الباحث y

$$
\begin{aligned}
\mathrm{SD}_{\mathrm{y}} & =\sqrt{\frac{\sum y 2}{N}}=\sqrt{\frac{70,24}{18}} \\
& =\sqrt{3,902} \\
& =1,975
\end{aligned}
$$


Faruq Abdul Muid : Penyusunan Materi Pembelajaran untuk Meningkatkan Keterampilan Berbicara untuk Santri Pondok Yanabi'ul Ulum Walhikam

- يطلب الباحث SE (standard Error) من متغير x

$\mathrm{SE}_{\mathrm{M} 1}=\frac{\mathrm{SD}_{1}}{\sqrt{\mathrm{N}_{1}-1}}=\frac{2,114}{\sqrt{18-1}}=\frac{2,114}{\sqrt{17}}=\frac{2,114}{4,123}=0,513$

4- يطلب الباحث SE (standard Error) منغيرY

$\mathrm{SE}_{\mathrm{M} 2}=\frac{\mathrm{SD}_{2}}{\sqrt{\mathrm{N}_{2}-1}}=\frac{1,975}{\sqrt{18-1}}=\frac{1,975}{\sqrt{17}}=\frac{1,975}{4,123}=0,479$

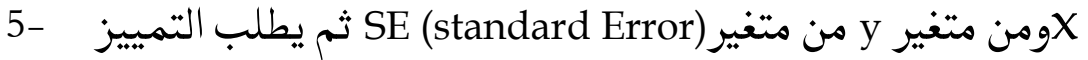

$\mathrm{SE}_{\mathrm{M} 1-\mathrm{M} 2}=\sqrt{\mathrm{SE}_{\mathrm{M} 1}^{2}+\mathrm{SE}_{\mathrm{M} 2}{ }^{2}}$

$=\sqrt{0,513^{2}+0,479^{2}}$

$=\sqrt{0,263+0,229}$

$=\sqrt{0,492}$

$=0,701$

6- $\quad$ ب, $\square^{\frac{80,42-70,24}{0,701}}=\frac{10,178}{0,701}=14,519=t_{0}=\frac{M_{1}-M_{2}}{S E_{M_{1}-M_{2}}}$

وهو :tويعطي التأويل عن

$\mathrm{df}=\left(\mathrm{N}_{1}+\mathrm{N}_{2}\right)-2$

$=(18+18)-2$

$=36-2$

$=34$

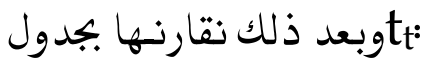

5 \% من جدو 5 =2,032

\% من جدول $1 t_{t}=2,728$

1\% أو في 5جدول في to أكبر من to ومن هنا يُعرف أن

$2,032>14,519<2,728$ 
Faruq Abdul Muid : Penyusunan Materi Pembelajaran untuk Meningkatkan Keterampilan Berbicara untuk Santri Pondok Yanabi'ul Ulum Walhikam

ذلك يدل على أن الفرضية الصفرية (Ho) مردودة والفرضية البدلية

(Ha) مقبولة، بمعنى يوجد فرق بين نتيجة الفصل التجريبي (x) باستخدام المادة المطورة وبين نتيجة الفصل الضبطي (y) بدون المادة المطورة. والتلخيص الذي نأخذه من هذا الباب أن هناك وجود الفعالية من استخدام المواد المطورة لترقية مهارة كلام الطلبة في الفصل الثاني الابتدائي بمعد"ينابيع العلوم و الحكم" الإسلامي سيدورسمو سورابايا

إنّ لإعداد المادة التعليمية لتعليم الكلام لطلاب بالفصل الثاني بـمعهد

ينابيع العلوم والحكم سيدورسمو سورابايا سبع خطوات . أولا جمع المعلومات في تعليم الكلام . ثانيا التخطيط. ثالثا إعداد المادة التعليمية لتعليم الكلام. رابعا مراجعة الخبراء ـ خامسا تجربة المادة لتعليم الكلام . سادسا تحسين المادة التعليمية لتعليم الكلام و سابعا تجربة إجراء المادة التعليمية لتعليم الكلام. المواد التعليمية المطورة لتعليم الكلام فعال لتنيمية مهارة كلام طلاب بالفصل

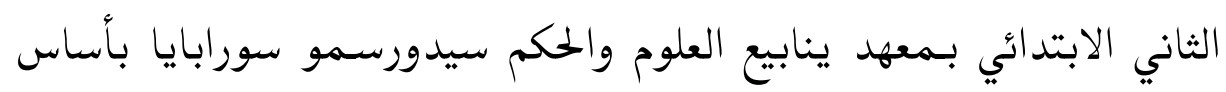

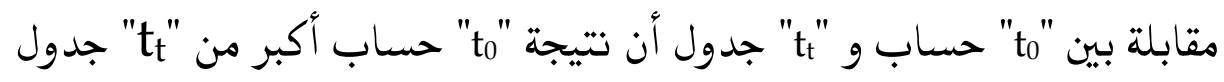

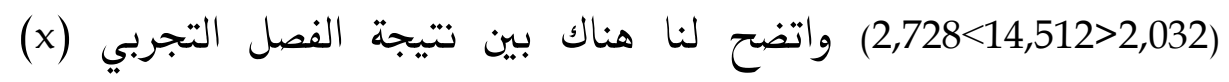
باستخدام المادة المطورة وبين نتيجة الفصل الضبطي (y) بدون المادة المطورة. ويدل متعادل نتائج الطلاب في الفصل التجربي r ع,.^^، ومتعادل نتائج الطلاب

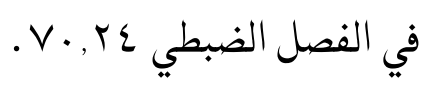


Faruq Abdul Muid : Penyusunan Materi Pembelajaran untuk Meningkatkan

Keterampilan Berbicara untuk Santri Pondok Yanabi'ul Ulum Walhikam

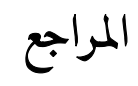

Ainin, Moh. Metodologi Penelitian Bahasa Arab. Surabaya: Hilal Pustaka, 2010.

Arikunto, Suharsismi. Prosedur Penelitian: Suatu Pendekatan Praktik.Jakarta: Rineka Cipta, 2006.

Arsyad, Azhar. Media Pembelajaran. Jakarta: Raja grafindo persada, 2013.

Hamid, Abdul. Uril Baharudin. Bisri Mustofa. Pembelajaran Bahasa Arab. Malang: UIN Malang Press, 2008.

Husni, Arman. "Pengembangan bahan ajar bahasa arab ". al ittijah, Vol. 02 No. 01. Januari-Juni.

Majid, Abdul. Perencanaan Pembelajaran: Mengembangkan Standar Kompetensi Guru. Bandung: Remaja Rosdakarya, 2013.

Muhid, Abdul. Analisis Statistik.Sidoarjo: Zifatama, 2012

Putra, Nusa, Research \& Development Penelitian dan Pengembangan: Suatu Pengantar, Jakarta: Raja Grafindo, 2012.

Rahardjito. Arief S. Sadima. R. Rahardjo. Anung haryono. Media Pendidikan: Pengertian, Pengembangan, dan Pemanfaatan. Jakarta: Raja Grafindo Persada, 2012.

Rosyidi, Abd wahab. Mamlu'atul Nikmah. Memahami konsep dasar pembelajaran bahasa arab. Malang: UIN Maliki, 2011.

Sanjaya, Wina. Penelitian Pendidikan: Jenis, Metode, dan Prosedur.Jakarta:kencana, 2014.

. Perencanaan dan Desain Sistem Pembelajaran. Jakarta: Kencana, 2010. 
Faruq Abdul Muid : Penyusunan Materi Pembelajaran untuk Meningkatkan Keterampilan Berbicara untuk Santri Pondok Yanabi'ul Ulum Walhikam

Surakhmad ،Winarno .Pengantar Penelitian Ilmiyah .Bandung: Tarsito, 1994.

بيهقي، محمد ـ الاختبارات في تعليم اللغة العربية. سيدوارجو : دوي فوترا

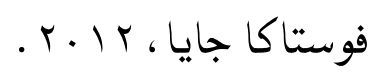

شحاتة، حسن . تعليم اللغة العربية بين النظرية والتطبيق . القاهرة : الدار المصرية اللبنانية, 1997 . 197

صيني ، محمود اسماعيل . عبد العزيز ، ناصف مصطفى • حسين ، مختار الطاهر . دليل المعلم

إلى استخد/م الصور والبطاقات في تعليم العربية ـ الرياض : مكتبة التربية العربي

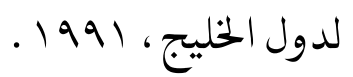

طاهر ، محمد • بيهقي، محمد ـ حنيفة ، أم . مسعود ، سلطان . المدخل إلى طرق تدريس العربية للاندونيسبيين ، سورابايا : جامعة سونان أمبيل مجديل

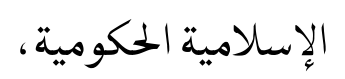

طعيمة، رشدي أحمد ـ تعليم العربية لغير الناطقين بها مناهجه وأساليبه، مصر : منصورات المنظمة الإسلامية للتربية والعلوم والثقافة ، 1919 ـ

تعليم العربية لغير الناطقين بها : مناهجه وأسالبه ـ الرباط :

$$
\text { منشورات }
$$


Faruq Abdul Muid : Penyusunan Materi Pembelajaran untuk Meningkatkan Keterampilan Berbicara untuk Santri Pondok Yanabi'ul Ulum Walhikam

$$
\text { المنطمة الإسامية للتربية والعلوم والثقافة ، } 9 \text { و 19 ـ }
$$

فوزان (ال) عبد الرحمن بن إبراهيم, إضاء/ت لمعلمي اللغة العربية لغير الناطقين

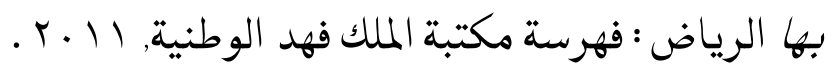

$$
\text { مجمع اللغة العربية :/لمعجم الوسيط . }
$$

مجيب (ال) أحمد عبد ، الألعاب الكامية اللسانية : دراستة صوتية تركيبية.

$$
\text { القاهرة : المكتبة الخانبي } 1999 \text {. }
$$

ناقة (ال) محمود كامل. طعيمة، رشدي أحمد . طرائق تدريم اللغة العربية

$$
\text { لغير الناطقبن بها ـ مصر : إيسيسكو, r . . . . }
$$

ناقة (ال) ، محمود كامل ، تعليم اللغة العربية الناطقين بلغات أخرى ـ المملكة

$$
\text { العربية السعودية : جامعة أم القرى ـ د .ن }
$$

يعقوب ، أميل بديع . موسوعة علوم اللغة العربية . بيروت : دار الكتب العلمية ، د.ن 